\title{
Residential alternatives to acute psychiatric hospital admission: systematic review
}

Brynmor Lloyd-Evans, Mike Slade, Dorota Jagielska and Sonia Johnson

\section{Background}

Reducing use of hospital wards and improving their quality are central aims of mental health service policy. However, no comprehensive synthesis is available of evidence on residential alternatives to standard acute psychiatric wards.

\section{Aims}

To assess the effectiveness and cost-effectiveness of and satisfaction with residential alternatives to standard acute in-patient mental health services.

\section{Method}

A systematic search identified controlled studies comparing residential alternatives with standard in-patient services. Studies were described and assessed for methodological quality. Results from higher quality studies are presented and discussed.

\section{Results}

Twenty-seven relevant studies were identified. Nine studies of moderate quality provide no contraindication to identified alternative service models and limited preliminary evidence that community-based alternatives may be cheaper and individuals more satisfied than in standard acute wards.

\section{Conclusions}

More research is needed to establish the effectiveness of service models and target populations for residential alternatives to standard acute wards. Community-based residential crisis services may provide a feasible and acceptable alternative to hospital admission for some people with acute mental illness.

\section{Declaration of interest}

None.
In-patient acute mental health services have been found to be unpopular with service users, ${ }^{1,2}$ often failing to address individuals' needs or provide a safe and therapeutic environment. ${ }^{3,4}$ Home treatment is not appropriate for all at times of acute illness because of levels of risk or adverse social circumstances, so residential acute services offering an alternative to standard in-patient care are of considerable interest. Several types of innovative residential acute service have been developed in Europe and North America over recent decades. ${ }^{5}$ However, their effectiveness remains uncertain. Two relevant Cochrane reviews have been published. Johnstone \& Zolese $^{6}$ review length of stay on acute wards, but include as brief-stay wards services with no maximum length of stay or admission for up to 4 weeks, arguably too similar to current standard care to be seen as an alternative to it. Joy \& Saylan ${ }^{7}$ have reviewed mother and baby units, finding no studies for inclusion. A number of reviews without meta-analyses identify some relevant studies. ${ }^{8-14}$ All however are either old, reliant on search strategies too limited to be considered systematic, or narrowly focused on a specific service model. There is no systematic synthesis of the current evidence regarding all types of residential and in-patient alternatives to standard in-patient care.

A recent UK survey proposed criteria to define a service as a residential alternative to standard acute in-patient care. ${ }^{15}$ This review uses these criteria and reviews the evidence for each type of alternative. The aims of the review are to examine the effectiveness and cost-effectiveness of and satisfaction with alternative services, and to identify the major research gaps.

\section{Method}

\section{Inclusion criteria}

Studies meeting the following criteria were included in the review.

(a) Study type: randomised controlled trials (RCTs), two-group non-randomised cohort studies or one-group interrupted time series studies providing a specific quantitative comparison of the effectiveness and/or acceptability of residential alternatives and standard acute in-patient services. (b) Participants: adults aged 16-65 years assessed by a mental health professional as needing acute in-patient admission.

(c) Interventions: residential acute mental health services that offer an alternative to standard acute psychiatric wards in one of the following five ways: based in the community (non-hospital services such as crisis houses); time limited (services offering admission with a time limit or planned maximum stay of 14 days or fewer); dedicated to a specific diagnostic group (e.g. first-episode psychosis or borderline personality disorder); dedicated to a specific sociodemographic group (e.g. wards for specific ethnic groups); implementing a specific therapeutic model involving changes to the working practices of more than one professional group.

(d) Outcomes: any outcome relating to clinical improvement or social functioning, service use, costs or cost-effectiveness, satisfaction with services.

\section{Search strategy}

A systematic search was undertaken of seven electronic databases Medline, PsycINFO, Web of Science, CINAHL, EMBASE, the Cochrane Library (Database of Abstracts of Reviews of Effects and Central Controlled Trials Register) and the National Health Service (NHS) Economic Evaluation Database - covering the period from January 1966 to February 2008. Search terms for acute, residential mental health services were combined with search terms for different types of alternatives: terms were searched in the title and abstract except where stated. No language restrictions were applied. The Medline search was conducted on PubMed as follows:

(a) crisis intervention[MeSH].exp OR crisis OR acute OR emergency

AND

(b) residential treatment $[\mathrm{MeSH}] \cdot \exp \mathrm{OR}$ residential OR hospital* OR inpatient* OR 'crisis house' OR 'community beds' OR 'crisis beds' 
AND

(c) mental disorders $[\mathrm{MeSH}] . \exp$ OR mental OR psychiatr ${ }^{\star}$

\section{AND}

(d) 'disorder specific' OR 'disorder-specific' OR specialist OR 'socio-demographic' OR sociodemographic OR ethnic ${ }^{\star}$ OR disabled OR disability OR 'visual ${ }^{\star}$ impair $^{\star}$ ' OR blindness OR deaf OR 'mother and baby' OR 'parent and child' OR 'therapeutic model' OR 'model of care' OR alternative OR innovative OR 'brief admission' OR 'brief stay' OR 'short stay' OR 'time limited' OR community OR 'non-hospital' OR 'sponsor homes' OR 'accredited accommodation' OR Soteria OR ('crisis intervention' AND Trieste) OR 'Tidal Model' OR 'refocusing model'.

Search terms were modified as necessary to search other databases. Reference lists of all included articles and review articles were also hand searched. 'Grey' literature was searched through directories of conference proceedings and additional unpublished studies or papers in press were sought by contacting experts within the field.

\section{Data abstraction}

Two of the authors (B.L.-E. and D.J.) independently scanned titles from all identified studies and from abstracts where relevant and available, then retrieved and read the full text of all potentially relevant studies. Queries about inclusion were discussed and any disagreement resolved by a third reviewer (S.J.). Study details, including type of study, service and participant characteristics, duration of study period and study outcomes, were collected using a standard data extraction form.

\section{Quality assessment}

The methodological quality of each study included in the review was assessed using a standard form adapted from the quality assessment tool of Thomas. ${ }^{16}$ Studies were rated as strong, moderate or weak regarding potential selection bias, allocation bias, accounting for confounders, masking, data collection methods and withdrawals, according to the criteria set out in the dictionary accompanying the quality assessment tool. ${ }^{16}$ The analysis strategy and intervention integrity of studies were also noted.

Operational criteria were created from quality ratings to distinguish studies of high, moderate and low quality overall. Studies that were rated as high quality reported allocation concealment during randomisation, analysed data based on intention-to-treat and rated strong in all domains in the Thomas tool bar masking. All other RCTs were rated as moderate quality, as were non-randomised studies which demonstrated no significant difference or adjusted in analyses for difference between experimental and control groups for the confounder of severity of illness at admission and rated at least moderate for all Thomas criteria assessed except masking.

\section{Reporting of study results}

This review includes outcomes only from studies that were rated as moderate or high quality. Outcomes are reported from all these studies: mean figures for service use and cost data are presented if reported; effect size and $P$-values are reported for all outcomes where there is a significant difference between alternative and standard services.

\section{Results}

Twenty-seven studies were identified for inclusion in the review, of which nine were rated as moderate or high quality. Figure 1 summarises the study flow through the review.

\section{Types of service studied}

The review identified studies of community-based ${ }^{17-31}$ and timelimited $^{32-38}$ services, and services with a specific therapeutic model. ${ }^{39-43}$ No studies of in-patient services for specific diagnostic or sociodemographic groups were found, although some studies of community-based services also included clinical or sociodemographic inclusion criteria for participants.

\section{Community-based services}

Fifteen studies of community-based services published from 1969-2006 were identified (Table 1; see online Table DS1 for a more detailed version of this table). Eleven of these were of US services.

A range of non-hospital service models have been evaluated. Four studies ${ }^{21,25,26,29}$ concern Soteria houses. Developed by Loren Mosher in California in the 1970 s, ${ }^{44}$ Soteria services provided care for people with first- or second-episode psychosis in informal settings. Primary staff were not clinically trained and worked long shifts $(36-48 \mathrm{~h})$ designed to help them to attune to and engage with residents. Staff and residents shared responsibility for household tasks and there was minimal reliance on antipsychotic medication. The model has been replicated more recently in a number of European countries (Switzerland, Germany, Sweden, Hungary, Finland), and evaluated primarily by Luc Ciompi and colleagues in Bern, Switzerland. ${ }^{25,26}$ Other crisis hostels described in studies in this review also provide care in small, homely settings, typically about 8 - to 12 -bedded. Services display variation in closeness of links with statutory services. Boardman et al ${ }^{19}$ describe a residential unit embedded within a community mental health resource centre, staffed by clinically qualified mental health

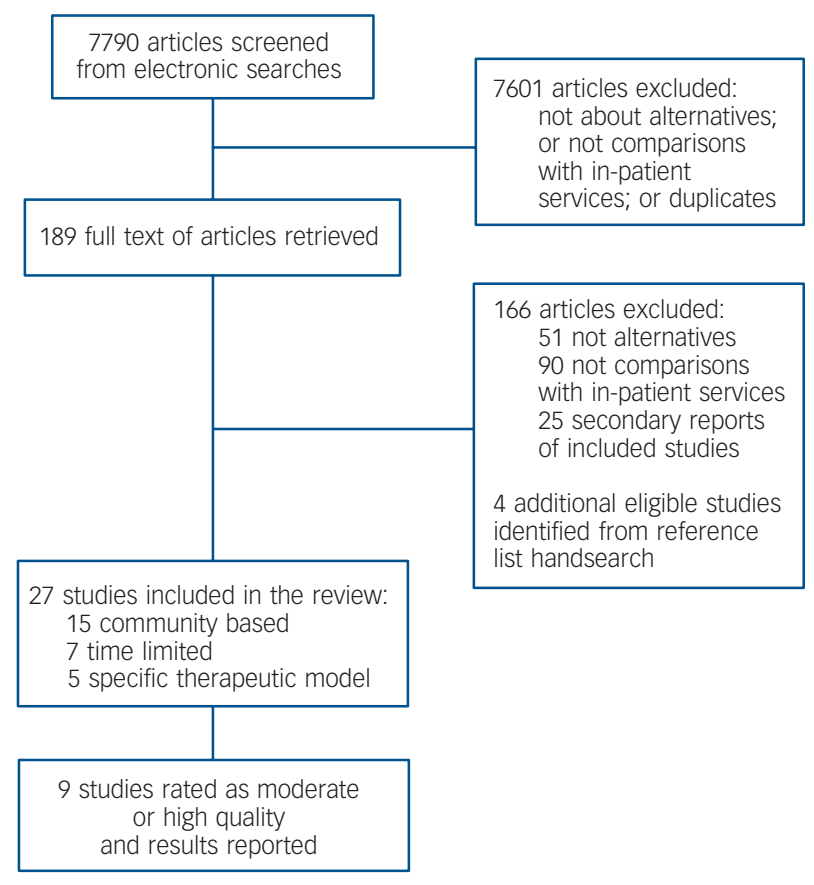

Fig. 1 Selection of studies for inclusion in systematic review. 


\begin{tabular}{|c|c|c|c|c|}
\hline Study reference & Service description & Study design and duration & $\begin{array}{l}\text { Outcomes } \\
\text { assessed }^{\text {b }}\end{array}$ & $\begin{array}{l}\text { Quality rating and } \\
\text { main limitations }{ }^{c}\end{array}$ \\
\hline Timko et $a l^{17}$ (2006) & $\begin{array}{l}\text { Veterans' community residential } \\
\text { facilitites, California, USA }\end{array}$ & $\begin{array}{l}\text { RCT } \\
\text { 30-day follow-up (from discharge) }\end{array}$ & $1,2,4$ & $\begin{array}{l}\text { Moderate } \\
1,2\end{array}$ \\
\hline Hawthorne et a/18 (2005) & $\begin{array}{l}6 \text { crisis hostels (11-14 bedded), } \\
\text { San Diego, USA }\end{array}$ & $\begin{array}{l}\text { RCT } \\
\text { 2-month follow-up }\end{array}$ & $1,2,3,4$ & $\begin{array}{l}\text { Moderate } \\
1,2,7 \text { (some satisfaction } \\
\text { data collected by service } \\
\text { staff) }\end{array}$ \\
\hline Boardman et al ${ }^{19}$ (1999) & $\begin{array}{l}\text { Community mental health centre } \\
\text { beds, UK }\end{array}$ & $\begin{array}{l}\text { Prospective non-randomised } \\
\text { quasi-experiment } \\
\text { 1-year follow-up }\end{array}$ & $1,2,3,4$ & $\begin{array}{l}\text { Moderate } \\
1,2\end{array}$ \\
\hline Fenton et al ${ }^{20}$ (1998) & $\begin{array}{l}\text { Crisis hostel (8 beds), Maryland, } \\
\text { USA }\end{array}$ & $\begin{array}{l}\text { RCT } \\
\text { 6-month follow-up }\end{array}$ & $1,2,3,4$ & $\begin{array}{l}\text { Moderate } \\
1\end{array}$ \\
\hline $\begin{array}{l}\text { Mosher et al21 (1995) } \\
\text { (Soteria study 2) }\end{array}$ & $\begin{array}{l}\text { Soteria crisis hostel, California, } \\
\text { USA }\end{array}$ & $\begin{array}{l}\text { RCT } \\
\text { 6-week follow-up }\end{array}$ & 1 & $\begin{array}{l}\text { Moderate } \\
1,2,6\end{array}$ \\
\hline Polak \& Kirby ${ }^{22}$ (1976) & $\begin{array}{l}\text { Adult family placement, Colorado, } \\
\text { USA }\end{array}$ & $\begin{array}{l}\text { RCT } \\
\text { 4-month follow-up }\end{array}$ & 1,3 & $\begin{array}{l}\text { Moderate } \\
1,2,3\end{array}$ \\
\hline Readhead et a ${ }^{23}$ (2002) & Adult family placements, UK & $\begin{array}{l}\text { Interrupted time series study } \\
\text { 1-year comparison period }\end{array}$ & 2,4 & $\begin{array}{l}\text { Low } \\
2,3\end{array}$ \\
\hline Hawthorne et a $\left.\right|^{24}$ (1999) & 5 crisis hostels, San Diego, USA & $\begin{array}{l}\text { Prospective non-randomised } \\
\text { quasi-experiment } \\
\text { 4-month follow-up }\end{array}$ & $1,2,3$ & $\begin{array}{l}\text { Low } \\
1,2,4\end{array}$ \\
\hline Ciompi et al ${ }^{24}$ (1993) & Soteria crisis hostel, Switzerland & $\begin{array}{l}\text { Prospective non-randomised } \\
\text { quasi-experiment } \\
\text { 2-year follow-up }\end{array}$ & $1,2,4$ & $\begin{array}{l}\text { Low } \\
2,3\end{array}$ \\
\hline Ciompi et al²6 (1992) & Soteria crisis hostel, Switzerland & $\begin{array}{l}\text { Non-randomised quasi-experiment } \\
\text { (not stated if retrospective) } \\
\text { 6-week follow-up }\end{array}$ & 1,4 & $\begin{array}{l}\text { Low } \\
2,3\end{array}$ \\
\hline Rappaport et al ${ }^{27}$ (1987) & 45 bed crisis hostel, California, USA & $\begin{array}{l}\text { Retrospective non-randomised } \\
\text { cohort study } \\
\text { Assessment at discharge }\end{array}$ & 1 & $\begin{array}{l}\text { Low } \\
1,2,4\end{array}$ \\
\hline Bittle et $a^{28}(1986)$ & $\begin{array}{l}2 \text { crisis hostels ( } 10 \text { bedded), Illinois, } \\
\text { USA }\end{array}$ & $\begin{array}{l}\text { Retrospective non-randomised } \\
\text { cohort study } \\
\text { 40-month follow-up }\end{array}$ & 2 & $\begin{array}{l}\text { Low } \\
2,3\end{array}$ \\
\hline $\begin{array}{l}\text { Mosher \& Menn }{ }^{29} \text { (1978) } \\
\text { (Soteria study 1) }\end{array}$ & Soteria crisis hostel, California, USA & $\begin{array}{l}\text { Prospective non-randomised } \\
\text { (pseudo-randomised) } \\
\text { quasi-experiment } \\
\text { 2-year follow-up }\end{array}$ & 1,2 & $\begin{array}{l}\text { Low } \\
1,2,4\end{array}$ \\
\hline Brook $^{30}$ (1973) & $\begin{array}{l}\text { Crisis hostel, Denver, USA } \\
\text { (time limited to } 7 \text { days) }\end{array}$ & $\begin{array}{l}\text { Non-randomised cohort study } \\
\text { (not specified if retrospective) } \\
\text { 6-month follow-up }\end{array}$ & 1,2 & $\begin{array}{l}\text { Low } \\
2,3\end{array}$ \\
\hline Goveia \& Tutko 31 (1969) & Crisis hostel, California, USA & $\begin{array}{l}\text { Prospective non-randomised } \\
\text { quasi-experiment (some but not } \\
\text { all participants randomised) } \\
\text { 12-month follow-up }\end{array}$ & $1,2,3$ & $\begin{array}{l}\text { Low } \\
1,2,3,4,5\end{array}$ \\
\hline \multicolumn{5}{|c|}{$\begin{array}{l}\text { RCT, randomised controlled trial. } \\
\text { a. A more detailed version of this table (Table DS1) is available online. } \\
\text { b. Domains: } 1 \text {, improvement; } 2 \text {, service use; } 3 \text {, satisfaction; } 4 \text {, cost. } \\
\text { c. Key to a spects of study quality: } 1 \text {, analysis based on completer data not all intended to treat; } 2 \text {, allocation concealment unclear (RCTs); not randomised (non-RCTs); } 3 \text {, confounders } \\
\text { (including severity of illness) not measured and if necessary adjusted for in analysis; } 4 \text {, more than } 40 \% \text { of potential participants declined to participate or number not stated; } 5 \text {, more } \\
\text { than } 40 \% \text { participants lost at follow-up; } 6 \text {, unspecified or previously unpublished outcome measure; } 7 \text {, other. }\end{array}$} \\
\hline
\end{tabular}

professionals including supervision by psychiatrists; Timko et al ${ }^{17}$ by contrast describe independently run services contracted by statutory agencies. Two studies in this review ${ }^{17,18}$ describe services funded by American Veterans Associations, providing care mainly to veterans. Apart from Soteria hostels, crisis houses in studies in this review are not described as guided by a clear, manualised model of care: types of care provided are not described in detail.

Placement with individual families is the other model of community-based alternative to hospital identified in this review. Polak \& Kirby evaluated family sponsor homes developed in the 1970s in Denver Colorado, ${ }^{22}$ where host families supported one or two acutely ill people, with training and assistance from local crisis services. This scheme specifically aimed to divert people from acute hospital admission. Support included involving individuals in a normal family environment with participation in meals and other domestic tasks and activities. The model has been used on a small scale in Powys, Wales in the last decade. ${ }^{23}$

Time-limited services

Seven studies evaluated time-limited hospital in-patient services ranging from 1 day to 8 days maximum planned admission (Table 2). Studies dated from 1966 to 1996 and evaluated services in North America and the UK. All the brief-stay wards in studies in this review were located within larger hospital complexes and accepted general acute admissions. Brief-stay services report an aim to increase the intensity with which care was provided compared with standard acute wards (e.g. providing assessment, medication review, help solving psychosocial problems, after-care 
Table 2 Characteristics of studies of time-limited services

\begin{tabular}{|c|c|c|c|c|c|}
\hline Study reference & Service description & Study design and duration & $\begin{array}{l}\text { Participants and total } n \\
\text { (alternative } n / \text { comparison } n \text { ) }\end{array}$ & $\begin{array}{l}\text { Outcomes } \\
\text { assessed }^{\text {a }}\end{array}$ & $\begin{array}{l}\text { Quality rating and } \\
\text { main limitations }{ }^{b}\end{array}$ \\
\hline Olfson $^{32}$ (1990) & $\begin{array}{l}\text { 5-day time-limited crisis } \\
\text { admission ward, New England, } \\
\text { USA }\end{array}$ & $\begin{array}{l}\text { Prospective non-randomised } \\
\text { quasi-experiment } \\
\text { 3-month follow-up }\end{array}$ & $\begin{array}{l}\text { Adults assessed as requiring acute } \\
\text { admission: diagnosis of schizo- } \\
\text { phrenia, one or more previous } \\
\text { admissions, stable housing, no } \\
\text { current substance misuse or major } \\
\text { medical problems } \\
n=26(8 / 18)\end{array}$ & 1,2 & $\begin{array}{l}\text { Moderate } \\
2\end{array}$ \\
\hline $\begin{array}{l}\text { Hirsch et } a l^{33} \\
\text { (1979) }\end{array}$ & $\begin{array}{l}\text { 8-day target hospital } \\
\text { admission ward, UK }\end{array}$ & $\begin{array}{l}\text { RCT } \\
\text { 1-year follow-up }\end{array}$ & $\begin{array}{l}\text { Adults aged } 16+\text { requiring acute } \\
\text { admission } \\
\text { No diagnosis of brain injury or major } \\
\text { physical health problem } \\
n=224(115 / 109)\end{array}$ & 1,2 & $\begin{array}{l}\text { Moderate } \\
1,2\end{array}$ \\
\hline Herz et $a l^{34}$ (1975) & $\begin{array}{l}\text { 1-week target hospital } \\
\text { admission ward, New York, } \\
\text { USA }\end{array}$ & $\begin{array}{l}\text { RCT } \\
\text { 7-month follow-up }\end{array}$ & $\begin{array}{l}\text { Adults aged } 16+\text { requiring acute } \\
\text { admission who live with a } \\
\text { responsible adult, have a diagnosis } \\
\text { of mental illness. Limitations on } \\
\text { comorbidity } \\
n=175 \text { (51: brief hospital; 61: brief } \\
\text { hospital and day care; 63: standard } \\
\text { hospital) }\end{array}$ & 1,2 & $\begin{array}{l}\text { Moderate } \\
2,3\end{array}$ \\
\hline $\begin{array}{l}\text { Schneider } \\
\& \text { Ross }^{35} \text { (1996) }\end{array}$ & $\begin{array}{l}\text { 3-day crisis admission } \\
\text { ward, Connecticut, USA }\end{array}$ & $\begin{array}{l}\text { Retrospective } \\
\text { non-randomised cohort } \\
\text { 30-day follow-up }\end{array}$ & $\begin{array}{l}\text { Adults assessed as requiring } \\
\text { acute admission } \\
n=1370(590 / 780)\end{array}$ & 2 & $\begin{array}{l}\text { LoW } \\
2,3\end{array}$ \\
\hline $\begin{array}{l}\text { Ianzito et }\left.a\right|^{36} \\
\text { (1978) }\end{array}$ & $\begin{array}{l}\text { 24-h admission ward, } \\
\text { Massachusetts, USA }\end{array}$ & $\begin{array}{l}\text { Retrospective non-randomised } \\
\text { cohort study } \\
\text { 2-week follow-up }\end{array}$ & $\begin{array}{l}\text { Adults assessed as requiring } \\
\text { acute admission } \\
n=184(83 / 101) \text { (also } 193 \\
\text { non-admitted patients evaluated) }\end{array}$ & 1,3 & $\begin{array}{l}\text { Low } \\
2,3,6\end{array}$ \\
\hline $\begin{array}{l}\text { Voineskos } \\
\text { et } a l^{37} \text { (1972) }\end{array}$ & $\begin{array}{l}\text { 3-day crisis admission } \\
\text { ward, Canada }\end{array}$ & $\begin{array}{l}\text { Retrospective non-randomised } \\
\text { cohort } \\
\text { Duration of initial admission } \\
\text { assessed }\end{array}$ & $\begin{array}{l}\text { Adults assessed as requiring } \\
\text { acute admission } \\
n=868(439 / 429)\end{array}$ & 2 & $\begin{array}{l}\text { Low } \\
2,3\end{array}$ \\
\hline Mendel $^{38}$ (1966) & $\begin{array}{l}\text { 7-day time-limited } \\
\text { admission ward, California, } \\
\text { USA }\end{array}$ & $\begin{array}{l}\text { Prospective non-randomised } \\
\text { quasi-experiment } \\
\text { 18-month follow-up }\end{array}$ & $\begin{array}{l}\text { Adults } 18+\text { assessed as requiring } \\
\text { acute admission: diagnosis of } \\
\text { schizophrenia, admission from } \\
\text { community, voluntary or } \\
\text { on } 72-\text { h section } \\
n=443(114 / 329)\end{array}$ & 1,2 & $\begin{array}{l}\text { Low } \\
1,2,3,5\end{array}$ \\
\hline
\end{tabular}

planning within the period of a brief admission), but distinctly different interventions are not described.

\section{Services with a distinctive therapeutic model}

Five studies of services with a specific therapeutic model involved one of two UK nursing-led models of care developed in the last decade, the Tidal model or the Refocusing model (Table 3). The Tidal model, developed by Phil Barker in the $1990 \mathrm{~s}^{45}$ seeks to avoid a perceived reductionist approach of relating to people purely as patients with symptoms that need to be treated, by valuing people's own narrative of illness and perception of problems. Frequent, collaborative contact between staff and patients is encouraged through regular assessment of problems and goals. This involves documenting individuals' expressed needs and problems verbatim. The Refocusing Model, developed on acute wards in Bradford, UK, in the late 1990s, ${ }^{43}$ increased nurses' authority to take risk management decisions and thus minimise or eradicate formal observations on wards, with time instead spent on more collaboratively agreed contact between staff and patients.

\section{Study characteristics}

Twenty-seven studies included in this review comprised 7 RCTs, 7 non-randomised prospective quasi-experimental studies and 13 before/after comparison studies. Most were of small or medium size, only four studies having more than 250 participants. ${ }^{24,28,37,38}$ Duration of studies ranged from the period of admission only up to 40-month follow-up.

No studies identified by this review were assessed as high quality. Nine studies were rated as moderate quality, including two well-designed quasi-experimental studies in addition to seven RCTs. Three of these studies were of brief-stay wards $s^{32-34}$ and six of community-based services, residential crisis beds ${ }^{17-21}$ or family placement. ${ }^{22}$ None rated strong on all criteria of the Thomas assessment tool. ${ }^{16}$ Only one study ${ }^{20}$ clearly described allocation concealment procedures during randomisation. Where participants were lost to follow-up, no studies based analysis on intention-to-treat; all provided completer data only. Reported levels of loss of participants during the course of studies varied substantially for studies of moderate quality. Only two ${ }^{22,34}$ included in outcomes data all potential participants assessed as eligible; reported overall attrition rates on individual outcomes 


\begin{tabular}{|c|c|c|c|c|c|}
\hline Study reference & Service description & Study design and duration & $\begin{array}{l}\text { Participants and total } n \\
\text { (alternative } n \text { /comparison } n \text { ) }\end{array}$ & $\begin{array}{l}\text { Outcomes } \\
\text { assessed }^{\text {a }}\end{array}$ & $\begin{array}{l}\text { Quality rating and } \\
\text { main limitations }{ }^{\mathrm{b}}\end{array}$ \\
\hline $\begin{array}{l}\text { Berger et a }{ }^{39} \\
(2006)\end{array}$ & Tidal model ward, Canada & $\begin{array}{l}\text { Interrupted time series study } \\
\text { 6-month comparison period: } \\
\text { outcomes during admission } \\
\text { assessed }\end{array}$ & $\begin{array}{l}\text { Adults on an acute admission } \\
\text { ward who consent to participate } \\
n=46 \text { (not stated) }\end{array}$ & 3 & $\begin{array}{l}\text { Low } \\
1,2,3,4\end{array}$ \\
\hline $\begin{array}{l}\text { Lafferty \& } \\
\text { Davidson }{ }^{40} \text { (2006) }\end{array}$ & $\begin{array}{l}\text { Tidal model ward, } \\
\text { Glasgow, UK }\end{array}$ & $\begin{array}{l}\text { Interrupted time series study } \\
\text { 1-year comparison period }\end{array}$ & $\begin{array}{l}\text { Adults on an acute ward } \\
n \text { not stated (service level data } \\
\text { only collected) }\end{array}$ & $1 / 3$ & $\begin{array}{l}\text { Low } \\
2,3\end{array}$ \\
\hline $\begin{array}{l}\text { Gordon et al41 } \\
\text { (2005) }\end{array}$ & $\begin{array}{l}\text { Tidal model ward, } \\
\text { Birmingham, UK }\end{array}$ & $\begin{array}{l}\text { Retrospective non-randomised } \\
\text { cohort study } \\
\text { 1-year comparison period: } \\
\text { outcomes during admission } \\
\text { assessed }\end{array}$ & $\begin{array}{l}\text { Adults on an acute ward } \\
n \text { not stated (service level data } \\
\text { only collected) }\end{array}$ & $1 / 3$ & $\begin{array}{l}\text { LoW } \\
2,3\end{array}$ \\
\hline $\begin{array}{l}\text { Stevenson et } a l^{42} \\
(2002)\end{array}$ & $\begin{array}{l}\text { Tidal model ward, } \\
\text { Newcastle, UK }\end{array}$ & $\begin{array}{l}\text { Interrupted time series study } \\
\text { 6-month comparison period } \\
\text { Duration of initial admission } \\
\text { assessed }\end{array}$ & $\begin{array}{l}\text { Adults on an acute ward } \\
n=150(81 / 69)\end{array}$ & 2 & $\begin{array}{l}\text { Low } \\
2,3\end{array}$ \\
\hline $\begin{array}{l}\text { Dodds \& Bowles }{ }^{43} \\
\text { (2001) }\end{array}$ & $\begin{array}{l}\text { Refocusing model ward, Brad- } \\
\text { ford, UK }\end{array}$ & $\begin{array}{l}\text { Interrupted time series study } \\
\text { 6-month comparison period: } \\
\text { outcomes during admission } \\
\text { assessed }\end{array}$ & $\begin{array}{l}\text { Adults on an acute ward } \\
n \text { not stated (service level data } \\
\text { only collected) }\end{array}$ & 1 & $\begin{array}{l}\text { LOW } \\
2,3\end{array}$ \\
\hline
\end{tabular}

in other moderate-quality studies range from 3 to $52 \%$ of potential participants. Service use data, gathered from routinely collected records, was generally more comprehensive than assessment of participants' functioning or satisfaction.

Of the 18 remaining studies assessed as low quality, 15 did not adequately measure or adjust for confounders. Five had high risk of selection bias (more than $40 \%$ of those eligible declining to participate); two had unacceptably high withdrawal rates (more than 40\%) for all outcomes and one used only unpublished outcome measures. Full details of the quality assessment of all studies can be found in online Table DS2.

\section{Study outcomes}

Outcomes assessed and results from studies of higher (moderate) quality found in this review are presented in Table 4 (a more detailed version, including details of the outcomes assessed, can be found as online Table DS3).

All six moderate-quality studies of community-based alternatives reported measures of symptoms and/or global improvement: four ${ }^{17,20-22}$ found no significant differences from standard services, whereas two ${ }^{18,19}$ found some results favouring alternatives and some showing no significant difference. Three ${ }^{18,19,22}$ out of four studies that assessed satisfaction reported moderately and significantly greater satisfaction with the alternative than the standard service. Three ${ }^{17,18,20}$ out of four studies that assessed cost also reported results favouring the alternative service. The exception was the community mental health team community beds assessed by Boardman et al: ${ }^{19}$ a statutory service staffed by qualified mental health professionals, in contrast to the other community-based services described in this review, this service cost the NHS more per patient than standard acute wards, although with no significant overall difference to public services. Only with regard to service use were any results favourable to standard care: two of three studies reported length of index admission greater at community alternatives than standard wards, $;^{17,20}$ one of four found in-patient bed-days, including index admission, over the study follow-up period significantly fewer for standard services. ${ }^{17}$

Of the three moderate-quality studies of time-limited alternatives, only one found the brief-stay ward able to discharge individuals within the planned admission period and significantly more quickly than standard wards. ${ }^{34}$ One study $^{32}$ found a majority of people required transfer to a standard ward at the end of the brief-stay period; one study ${ }^{33}$ found the 8 -day planned admission period not rigorously adhered to and mean length of stay not significantly shorter than standard care. None found any significant differences in clinical outcomes or readmission rates. All five low-quality studies of services using a distinctive therapeutic model reported some outcomes favourable to alternative services regarding patient satisfaction or levels of untoward incidents on wards.

\section{Discussion}

\section{Findings of the review}

Current research is insufficient to provide convincing evidence about the effectiveness or acceptability of residential alternatives to standard acute in-patient mental health services. No studies of services for specific demographic groups or people with specific diagnoses were identified, despite literature providing descriptions of some such services as promising service models, e.g. mother and baby units ${ }^{46}$ or psychosis, affective disorder and personality disorder wards. ${ }^{47}$ Studies of services with a distinctive therapeutic model were all of low quality, failing to account for differences between groups in analysis. The before and after comparison provided by most studies of services with a distinctive therapeutic model and their lack of stated primary outcomes also exacerbate risks of reporting and publication biases. The feasibility of briefstay acute wards is brought into question by the fact that in three moderate-quality studies, in only one ${ }^{34}$ was the alternative service able to discharge a majority of individuals within the planned admission period. The applicability of this finding to contemporary 
Table 4 Results from studies of moderate or high quality ${ }^{\mathrm{a}}$

\begin{tabular}{|c|c|}
\hline Study reference & Results \\
\hline \multicolumn{2}{|l|}{ Community-based services } \\
\hline \multirow[t]{3}{*}{ Timko et al17 (2006) } & Favours alternative: total out-patient visits (104 v. 130: $P<0.001$ ), 1-year cost ( $\$ 22000$ v. $\$ 33000: P=0.002$ ) \\
\hline & $\begin{array}{l}\text { Favours standard service: length of index admission ( } 26 \text { v. } 55 \text { days: } P<0.001) \text {, } 1 \text {-year total in-patient bed days } \\
\text { (78 v. } 86 \text { days: } P<0.01 \text { ) }\end{array}$ \\
\hline & No significant difference: ASI psychiatric subscale score at 1 year \\
\hline \multirow[t]{2}{*}{ Hawthorne et al ${ }^{18}$ (2005) } & $\begin{array}{l}\text { Favours alternative: discharge SF-36V }(P=0.02) \text { and POC }(P=0.05) \text { scores, cost of index admission }(P=0.001) \text {, } \\
\text { homelessness }(P=0.001) \text { at discharge }\end{array}$ \\
\hline & $\begin{array}{l}\text { No significant difference: discharge PANSS and ASI scores, PANSS, SF-36V, ASI scores, homelessness and number of } \\
\text { readmissions at 2-month follow-up }\end{array}$ \\
\hline \multirow[t]{2}{*}{ Boardman et al/19 (1999) } & Favours alternative: GAF $(P=0.02), \operatorname{HRSD}(P=0.01)$, PSE $(P=0.001)$, VSSS overall satisfaction $(P=0.02)$ \\
\hline & $\begin{array}{l}\text { No significant difference: HoNOS, SBS, CAN, length of index admission, number readmitted in 12-month follow-up, } \\
\text { cost to all public services (although cost to NHS significantly higher at alternative services) }\end{array}$ \\
\hline \multirow[t]{3}{*}{ Fenton et $a^{20}$ (1998) } & Favours alternative: cost of index admission significantly less ( $\$ 3046$ v. $\$ 5549$ : effect size $0.78, P<0.001$ ) \\
\hline & Favours standard service: length of index admission ( 12 v. 19 days: $P<0.002)$ \\
\hline & No significant difference: PANSS scores, satisfaction, 6-month costs, cost-effectiveness \\
\hline Mosher et al ${ }^{21}$ (1995) & No significant difference \\
\hline Polak \& Kirby²2 (1976) & $\begin{array}{l}\text { Favours alternative: satisfaction: TES score (patient report) at discharge }(P<0.001) \text { and 4-month follow up }(P<0.01) \\
\text { No significant difference: all measures of clinical improvement }\end{array}$ \\
\hline \multicolumn{2}{|l|}{ Time-limited services } \\
\hline Olfson $^{32}(1990)$ & No significant differences (only 3/8 participants discharged from brief-stay service within planned 5-day limit) \\
\hline Hirsch et al ${ }^{\beta 3}$ (1979) & No significant differences (median length of stay but not mean length significantly shorter at alternative) \\
\hline \multirow[t]{2}{*}{ Herz et al ${ }^{34}$ (1975) } & $\begin{array}{l}\text { Favours alternative: length of index admission ( } 9 \text { days v. } 50 \text { days: no } P \text { stated); in-patient days over 2-year follow-up } \\
\text { (47 v. 115: } P<0.001 \text { ) }\end{array}$ \\
\hline & $\begin{array}{l}\text { No significant difference: PSS or GAS total scores at } 3 \text { months or } 2 \text { years, number of participants readmitted over } 2 \text {-year } \\
\text { follow-up }\end{array}$ \\
\hline \multicolumn{2}{|c|}{$\begin{array}{l}\text { ASI, Addiction Severity Index; SF-36V, Health Survey - Short Form (Veterans Version); POC, Perceptions of Care Questionnaire; PANSS, Positive and Negative Symptom Scale; } \\
\text { GAF, Global Assessment of Functioning; HRSD, Hamilton Rating Scale for Depression; PSE, Present State Examination; VSSS, Verona Service Satisfaction Scale; HoNOS, Health of the } \\
\text { Nation Outcome Scale; SBS, Social Behaviour Schedule; CAN, Camberwell Assessment of Need; NHS, National Health Service; TES, Treatment Effectiveness Scale; PSS, Psychiatric } \\
\text { Status Schedule; GAS, Global Assessment Scale. } \\
\text { a. A more detailed version of this table is available online as Table DS3. }\end{array}$} \\
\hline
\end{tabular}

mental health service settings may be limited however, as the moderate-quality studies of time-limited services identified in this review all pre-date the advent of modern community resources such as home-treatment teams. The most recent study of timelimited services included in the review, from $1996,{ }^{35}$ found that $69 \%$ of those admitted to a 3 -day admission ward could be discharged into the community within this period, but the comparability of individuals with those admitted to general acute wards was unclear.

Despite the larger number of studies of community-based alternatives, the strength of evidence provided is nevertheless limited by the quality of included studies and the heterogeneity of services and participants studied. A crucial question is to what extent community-based alternatives can admit a population comparable with standard acute wards. All six moderate-quality studies of community-based services imposed different inclusion criteria for participants and all but one ${ }^{22}$ included some criteria (such as veterans only, consenting to participate, no admissions in the previous 12 months) beyond those normally required for real-life acute admission. Two of the studies specifically excluded detained patients; $;^{18,20}$ the remaining four did not report whether or how many participants were detained. The systematic exclusion from studies of some people who require acute admission and the not insignificant drop-out rates reported by some studies limit the strength and applicability of their results. Findings from studies of community-based services may only be applicable to a subgroup of people requiring acute admission, excluding some of those who are most severely unwell or least cooperative.

Notwithstanding its limitations, the evidence overall for community-based services retains the possibility that non-hospital residential crisis services are a useful service model: no clinical outcomes from studies in this review were worse than standard wards for community-based alternatives; the few differences reported tend to favour community-based models. That five studies successfully randomised participants assessed as requiring acute admission to either community alternatives or standard wards does suggest some similarity in populations served. As a whole, the studies provide preliminary evidence that for some people with acute mental health problems, community-based alternatives may be as effective and potentially less costly and more acceptable than standard in-patient wards. More generally, current research provides no contraindication to any of the types of alternatives included in this review.

\section{Methodological issues and limitations}

Residential alternatives are not clearly defined or described by a consistent terminology, providing a challenge for comprehensive retrieval of relevant studies. This review defined alternative services consistently with a current UK study of residential alternatives. ${ }^{15}$ Over-inclusive search terms were used in the initial search to minimise the risk of missing relevant studies, but this search found no studies that appeared to describe an innovative acute residential service and did not meet the review's inclusion criteria. This suggests the list of studies included in the review was relatively comprehensive.

In order to avoid ignoring available evidence in an underresearched area, non-randomised studies were included in the review. Assessment of study quality was conducted to inform consideration of the strength of evidence provided. The tool used in this review ${ }^{16}$ was recommended by Deeks et a l $^{48}$ in a review of quality assessment tools and recommended as suitable for randomised and non-randomised studies. It assesses the domains of quality identified as important in the most recent Cochrane handbook $^{49}$ (although with less detailed assessment of randomisation procedures) and additionally allows higher and lower quality non-randomised trials to be distinguished. Study ratings for masking were not used to assess overall study quality: masking 
of participants and guarantee of consistent concealment from raters of participants' care status were not considered possible for health services research of this type. In order to rate high overall, in addition to rating strong on all other assessment tool criteria, studies were required to report adequate allocation procedures during randomisation and analyse data based on intention-to-treat, as these two dimensions of quality have been identified as most associated with estimates of treatment effects. ${ }^{50}$ Only from studies rated moderate quality or above, based on the aspects of quality rated with the Thomas tool, ${ }^{16}$ were results presented in this paper. This provides some safeguard from creating a false impression of the weight and strength of evidence concerning alternative services by collating results from numerous poor-quality studies. However, the absence of any studies rated as highest quality in this review indicates the need for additional caution about the precision of results.

A meta-analysis of data from studies included in this review was initially planned. However, only a minority of moderate-quality studies, describing services of considerable heterogeneity, could provide any data usable in meta-analyses. In these circumstances, a meta-analysis was not considered appropriate. Data from moderate-quality studies which were potentially usable or not usable for meta-analyses are however presented in online Table DS4.

\section{Clinical implications}

Current research evidence provides clinicians and commissioners with only very limited guidance about effective models of acute in-patient mental healthcare. Several service models identified in this review - Soteria houses, adult family placements, time-limited wards - have been developed in more than one country or time period without ever becoming a well-established part of a national acute service system. This suggests some doubt about their sustainability and/or usefulness, although also a persisting perception of a need to seek alternatives to standard acute care. Residential services that can only cater for a proportion of people requiring acute admission may be perceived by service planners and commissioners as a luxury and be vulnerable to losing funding. The failure of alternative service models to endure may also reflect a reliance of innovative services on charismatic leaders and local champions, without whom they may not thrive. The community beds embedded in a community mental health resource centre evaluated by Boardman and colleagues ${ }^{19}$ allay some of these concerns. They were able to admit a reasonably high proportion $(65 \%)$ of people assessed as requiring acute admission during the study period, can accept detained patients and are still running currently, a decade later. Drayton Park, a women's crisis house in North London, has also been established for more than a decade and evaluated in qualitative studies as providing a valuable role in local acute care. ${ }^{51,52}$ This suggests that in a contemporary UK context, community crisis beds can constitute an important and sustainable part of local acute in-patient provision.

The dissatisfaction of many service users with standard psychiatric wards ${ }^{1,2}$ suggests a need for alternatives. The potential for emergency residential accommodation outside the hospital setting to improve service user choice and thus the acceptability of services, while relieving bed pressure on acute wards, was identified 10 years ago. ${ }^{53}$ Even if alternative service models can only divert a subgroup of people requiring acute admission, the increased scope this might bring for focusing appropriate facilities and expertise in in-patient services for a higher risk, predominantly detained client group is potentially useful. This review found no evidence against alternative models of care and, consistent with previous qualitative research, ${ }^{52,54}$ provides an indication that crisis beds in non-hospital settings may increase satisfaction with acute residential services for users. Certainly, this review provides no discouragement to service managers and commissioners to consider innovation in the provision of acute in-patient care.

\section{Future research}

A recent service mapping study indicates that alternatives, as defined in this review, constitute almost $10 \%$ of current acute in-patient beds in England, with each type of alternative included in this review represented. ${ }^{15}$ Many of the service models are far from new, with some to which papers included in the review relate dating back to the 1960s. Yet this review found only limited evidence for any and none for some types of alternative. This means that, where alternatives have been established, clinical practice is running ahead of the research evidence base. It goes some way towards explaining why some service models first described as promising several decades ago, such as crisis placements in family homes and brief-stay admission wards, have yet to be widely adopted despite the wish among service planners, clinicians and service users to develop alternatives to standard acute wards. The conclusion that there is a need and an opportunity for more research is an inescapable one in this area. A further research question beyond the scope of this review was how users of residential alternatives compare with people receiving crisis home treatment: information about the extent to which alternatives accommodate people who cannot be adequately treated at home would also illuminate their role and potential utility in the acute care system.

Only 9 of 27 studies identified for inclusion in this review were assessed as moderate quality and none as high quality, limiting the certainty with which any conclusions about the services being evaluated can be drawn. This highlights the need for research to be of good quality if it is to be useful. Key quality indicators that were absent from studies of moderate quality included in this review were arranging adequate allocation concealment and conducting analysis based on intention-to-treat and stating primary outcomes in advance. Insufficiently thorough description of participants' characteristics (e.g. whether people were detained or not) and inadequate reporting of variance in outcomes data were also common shortcomings. Only two studies ${ }^{17,32}$ included in the review provided detailed quantitative comparison of the content of care provided at alternative and standard services, although five more, ${ }^{21,25-27,29}$ including all the studies of Soteria houses, compared participants' medication use. More information about care provided would help identify differences in alternative service models and the extent and nature of difference from standard services, open the black box of service provision ${ }^{55}$ and aid understanding of service outcomes. The studies included in this review evaluate young services or recently established service innovations. Evaluation of more established, enduring alternatives would also be desirable, in order to investigate whether outcomes, perhaps especially satisfaction, are sustainable and not merely a function of service novelty.

There are particular challenges to conducting RCTs in acute mental health settings, where the need for immediate intervention makes both the logistics of randomisation and the process of informing participants and obtaining consent problematic. In such circumstances, quasi-experimental studies may be more feasible and have strong real-world applicability by evaluating outcomes for cohorts that include all service users. ${ }^{56}$ Two nonrandomised, natural experiment studies were assessed as moderate quality and reported results broadly congruent with those from 
RCTs included in the review. This indicates that a well-designed non-randomised study, which accounts for important confounders, may have a useful place in acute mental health service research. The development of clear protocols for ethically acceptable recruitment in mental health crises would also be very helpful, addressing issues such as how to conduct urgent randomisation out of hours when researchers are not available and how to deal with the often transient loss of capacity experienced by many people at the time of a crisis.

Compared with many models of community care, developments in acute in-patient care remain unevaluated. The treatment of people at times of crisis is clearly a crucial part of mental healthcare: establishing effective models of providing residential acute care should be a priority for future mental health services research.

Brynmor Lloyd-Evans, MSc, Department of Mental Health Sciences, University College London; Mike Slade, PhD, King's College London, Health Services and Population Research Department, Institute of Psychiatry, London; Dorota Jagielska, MA, Sonia Johnson, MD, Department of Mental Health Sciences, University College LA, Sonia Jon, UK
Lond

Correspondence: Brynmor Lloyd-Evans, Department of Mental Health Sciences, University College London, Charles Bell House, 67-73 Riding House Street, London W1W 7EJ, UK. Email: b.lloyd-evans@ucl.ac.uk

First received 11 Aug 2008, final revision 11 Aug 2008, accepted 3 Dec 2008

\section{Acknowledgements}

This report presents independent research commissioned by the National Institute for Health Research Service Delivery and Organisation Programme. The views expressed in this publication are those of the authors and not necessarily those of the NHS, the National Institute for Health Research or the Department of Health.

\section{References}

1 Quirk A, Lelliott P. What do we know about life on acute psychiatric wards in the UK? A review of the research evidence. Soc Sci Med 2001; 53: 1565-74.

2 Rose D. Users' Voices, The Perspectives of Mental Health Service Users on Community and Hospital Care. The Sainsbury Centre, 2001.

3 Muijen M. Acute hospital care: ineffective, inefficient and poorly organised. Psychiatr Bull 1999; 23: 257-9.

4 Barker S. Environmentally Unfriendly: Patients' Views of Conditions on Psychiatric Wards. MIND, 2000.

5 Warner R. Alternatives to the Hospital for Acute Psychiatric Treatment. American Psychiatric Press, 1995.

6 Johnstone $\mathrm{P}$, Zolese $\mathrm{G}$. Length of hospitalisation for people with severe mental illness. Cochrane Database Syst Rev 2000; 2: CD000384.

7 Joy CB, Saylan M. Mother and baby units for schizophrenia. Cochrane Database Syst Rev 2007; 1: CD006333.

8 Mattes JA. The optimal length of hospitalization for psychiatric patients: a review of the literature. Hosp Community Psychiatry 1982; 33: 824-8.

9 Arce AA, Vergare M. An overview of community residences as alternatives to hospitalization. Psychiatr Clin North Am 1985; 8: 423-36.

10 Stroul BA. Residential crisis services: a review. Hosp Community Psychiatry 1988; 39: 1095-9.

11 Braun P, Kochansky G, Shapiro R, Greenberg S, Gudeman J, Johnson S, et al. Overview: deinstitutionalisation of psychiatric patients, a critical review of outcome studies. Am J Psychiatry 1981; 138: 736-49.

12 McCabe L, Butterill D, Goering P. Residential crisis units. Are we missing out on a good idea? Can J Commun Ment Health 2004; 23: 65-74.

13 Grawe RW, Ruud T, Bjorngaard JH. Alternative emergency interventions in adult mental health care (in Norwegian). Tidsskr Nor laegeforen 2005; 125 : 3265-8.

14 Calton T, Ferriter M, Huband N, Spandler H. A systematic review of the Soteria paradigm for the treatment of people diagnosed with schizophrenia. Schizophr Bull 2008; 34: 181-92.

15 Johnson S, Gilburt H, Lloyd-Evans B, Osborn DPJ, Boardman J, Leese M, et al. In-patient and residential alternatives to standard acute psychiatric wards in England. Br J Psychiatry 2009; 194: 456-63.
16 Thomas H. Quality Assessment Tool for Quantitative Studies. Effective Public Health Practice Project, McMaster University, 2003.

17 Timko C, Chen S, Sempel J, Barnett, P. Dual diagnosis patients in community or hospital care: one-year outcomes and health care utilization and costs. J Ment Health 2006; 15: 163-77.

18 Hawthorne WB, Green EE, Gilmer T, Garcia P, Hough RL, Lee M, et al. $A$ randomized trial of short-term acute residential treatment for veterans. Psychiatr Serv 2005; 56: 1379-86.

19 Boardman AP, Hodgson RE, Lewis M, Allen K. North Staffordshire Community Beds Study: Iongitudinal evaluation of psychiatric in-patient units attached to community mental health centres. I: Methods, outcome and patient satisfaction. Br J Psychiatry 1999; 175: 70-8.

20 Fenton WS, Mosher LR, Herrell JM, Blyler CR. Randomized trial of general hospital and residential alternative care for patients with severe and persistent mental illness. Am J Psychiatry 1998; 155: 516-22.

21 Mosher LR, Vallone R, Menn A. The treatment of acute psychosis without neuroleptics: six-week psychopathology outcome data from The Soteria Project. Int J Soc Psychiatry 1995; 41: 157-73.

22 Polak PR, Kirby MW. A model to replace psychiatric hospitals. J Nerv Ment Dis 1976; 162: 13-22.

23 Readhead C, Henderson R, Hughes G, Nickless J. Accredited accommodation: an alternative to in-patient care in rural north Powys. Psychiatr Bull 2002; 26: $264-5$

24 Hawthorne WB, Green EE, Lohr JB, Hough R, Smith PG. Comparison of outcomes of acute care in short-term residential treatment and psychiatric hospital settings. Psychiatr Serv 1999; 50: 401-6.

25 Ciompi L, Kupper Z, Aebi E, Dauwalder HP, Hubschmid T, Trutsch K, et al. The pilot project 'Soteria Berne' in treatment of acute schizophrenic patients. II. Results of a comparative prospective follow-up study over 2 years. Nervenarzt 1993; 64: 440-50.

26 Ciompi L, Dauwalder HP, Maier C, Aebi E, Trütsch K, Kupper Z, et al. The pilot project 'Soteria Berne'. Clinical experiences and results. Br J Psychiatry 1992; 161(suppl 18): s145-53.

27 Rappaport M, Goldman H, Thornton P, Stegner B, Moltzen S, Hall K, et al. A method or comparing two systems of acute 24-hour psychiatric care. Hosp Community Psychiatry 1987; 38: 1091-5.

28 Bittle RG. Acute care treatment services (ACTS): a model program for providing acute psychiatric services in a homelike environment in an institutional setting. Behavioral Resident Treat 2006; 1: 275-88.

29 Mosher LR, Menn AZ. Community residential treatment for schizophrenia: two-year follow-up. Hosp Community Psychiatry 1978; 29: 715-23.

30 Brook BD. Crisis hostel: an alternative to psychiatric hospitalization for emergency patients. Hosp Community Psychiatry 1973; 24: 621-4.

31 Goveia LH, Tutko TA. Psychiatric Rehabilitation in a Community Center. Rehabilitation Mental Health Services, 1969.

32 Olfson M, Plotke G, Harding C, Jones J, Mayfield W. A controlled evaluation of inpatient crisis treatment for acute schizophrenia episodes. Psychiatr $Q$ 1990; 61: 143-54.

33 Hirsch S, Platt S, Knights A, Weyman A. Shortening hospital stay for psychiatric care: effect on patients and their families. BMJ 1979; 1: 442-6.

34 Herz M, Endicott J, Spitzer R. Brief hospitalization of patients with families: initial results. Am J Psychiatry 1975; 132: 413-8.

35 Schneider SE, Ross IM. Ultra-short hospitalization for severely mentally ill patients. Psychiatr Serv 1996; 47: 137-8.

36 Ianzito BM, Fine J, Sprague B, Pestana J. Overnight admission for psychiatric emergencies. Hosp Community Psychiatry 1978; 29: 728-30.

37 Voineskos G, Morrison MF, Jain RC. The introduction of a crisis unit in a mental hospital. Can Psychiatr Assoc J 1974; 19: 445-52.

38 Mendel W. Effect of length of hospitalization on rate and quality of remission from acute psychiatric episodes. J Nerv Ment Dis 1966; 143: 226-33.

39 Berger JL. Incorporation of the Tidal Model into the interdisciplinary plan of care - a program quality improvement project. J Psychiatr Ment Health Nurs 2006; 13: 464-7.

40 Lafferty S, Davidson R. Putting the person first. Ment Health Today 2006; March: 31-3.

41 Gordon W, Morton T, Brooks G. Launching the Tidal Model: evaluating the evidence. J Psychiatr Ment Health Nurs 2005; 12: 703-12.

42 Stevenson C, Barker P, Fletcher E. Judgement days: developing an evaluation for an innovative nursing model. J Psychiatr Ment Health Nurs 2002; 9: 271-6.

43 Dodds $\mathrm{P}$, Bowles N. Commentary. Dismantling formal observation and refocusing nursing activity in acute inpatient psychiatry: a case study. J Psychiatr Ment Health Nurs 2001; 8: 183-8. 
44 Mosher L. Soteria and other alternatives to acute psychiatric hospitalization: a personal and professional review. J Nerv Ment Dis 1999; 187: 142-9.

45 Barker P. The tidal model: a person-centred approach to psychiatric and mental health nursing. Perspect Psychiatr Care 2001; 37: 79-87.

46 Royal College of Psychiatrists. Perinatal Maternal Mental Health Services (Council Report CR88). Royal College of Psychiatrists, 2000.

47 Bonsack C, Borgeat F, Dubois A. Impact of mental health services' specialization by diagnosis in Lausanne. I. Qualitative Study. Ann Med Psychol 2001; 159: 645-51.

48 Deeks J, Dinnes J, D'Amico J, Sowden A, Sakarovitch C, Song F, et al. Evaluating non randomised intervention studies Health Technol Assess 2003; 27: $1-173$.

49 Cochrane Collaboration. Cochrane Handbook for Systematic Reviews of Interventions (eds J Higgins, S Green). Wiley, 2008.

50 Schulz K, Chalmers I, Hayes R, Altman D. Empirical evidence of bias: dimensions of methodological quality associated with estimates of treatment effects in controlled trials. JAMA 1995; 273: 408-12.
51 Killaspy H, Dalton J, McNicholas S, Johnson S. Drayton Park, an alternative to hospital admission for women in acute mental health crisis. Psychiatr Bull 2000; 24: 101-4.

52 Johnson S, Bingham C, Billings J, Pilling S, Morant N, Bebbington P, et al. Women's experiences of admission to a crisis house and to acute hospital wards: a qualitative study. J Ment Health 2004; 13: 247-62.

53 Sainsbury Centre for Mental Health. Acute Problems: A Survey of the Quality of Care in Acute Psychiatric Wards. The Sainsbury Centre, 1998.

54 Faulkner A, Petit-Zeman S, Sherlock J, Wallcraft J. Being There in a Crisis: A Report of the Learning from Eight Mental Health Crisis Services. The Mental Health Foundation and Sainsbury Centre for Mental Health, 2002.

55 Mechanic D. Emerging issues in international mental health services research. Psychiatr Serv 1996; 47: 371-5.

56 Gilbody S, Whitty P. Improving the delivery and organisation of mental health services: beyond the conventional randomised controlled trial. Br J Psychiatry 2002; 180: 13-8.

\section{Psychiatry in the movies}

\section{Paging Dr Love}

\section{Peter Byrne}

When women's roles in the war effort brought their empowerment, from The Flame Within (1936) to Lady in the Dark (1944), the institution of movie psychiatry reminded women of their place - as passive recipients of male wisdom and treatments. The female movie psychiatrist (The Flame Within) is frequently no different from the successful but unhappy career woman (Lady in the Dark) - their career will never bring the same fulfilment as a solid marriage. The female movie psychiatrist must be 'cured' by her love for her male patient. Dr Constance Peterson (Ingrid Bergman) has no difficulties helping her male amnesic patient, accused of murder, escape confinement. She marries him at the denouement of Spellbound (1945). Rather than list over a hundred films where girl (psychiatrist) falls for boy (patient), the challenge is to name those that deviate from this storyline. Classic Hollywood depicted women therapists as inadequate, personally and professionally: Knock on Wood (1954), A Perfect Furlough (1958), Wild in the Country (1961), A Very Special Favour (1965) and A Fine Madness (1966). Similar unhappy archetypes continue to yearn for their male patients in modern films: Mr Jones (1993), 12 Monkeys (1995) and The Jacket (2005). Perfect psychiatrist Dr Lowenstein must be rescued from her miserable personal life by an affair with her patient's brother in Prince of Tides (1991). In all these films, the only effective treatment is love. The audience are encouraged not to dwell on the boundary violations.

Male movie psychiatrists have romantic liaisons less frequently when taking into account the proportion of films where they are represented, but their behaviours are no less ludicrous: What's New Pussycat? (1965), Beyond Therapy (1987) and Color of Night (1994). Freud's provocative quote may help explain why male psychiatrists break fewer boundaries on the silver screen: 'for women, the level of what is ethically normal is different from what it is in men' - making the films here quoted truly Freudian. 